DOI 10.37882/2223-2982.2021.08.15

\title{
СОДЕРЖАТЕЛЬНО-ПРОЦЕССУАЛЬНЫЕ ОСОБЕННОСТИ ФОРМИРОВАНИЯ ПРАВОВЫХ УМЕНИЙ ДЕТЕЙ СТАРШЕГО ДОШКОЛЬНОГО ВОЗРАСТА
}

\section{CONTENT-PROCEDURAL FEATURES OF THE FORMATION OF CHILDREN'S LEGAL SKILLS SENIOR PRESCHOOL AGE \\ O. Eliseenko}

Summary: This article defines the need for the formation of legal skills of older preschool children in the context of changing goals and paradigms of domestic preschool education. The analysis of the content-procedural features of the pedagogical conditions for the formation of legal skills of older preschool children is carried out. The purpose of the study is to confirm the methodological and technological parameters of the implementation of the content-procedural features of the formation of legal skills of older preschool children.

Keywords: legal education, children of senior preschool age, formation of legal skills of children of senior preschool age, content-procedural features of the formation of legal skills of children.

\author{
Елисеенко Ольга Викторовна \\ старший преподаватель, Южно-Уральский \\ государственный университет (2. Челябинск) \\ eliseenkoov@gmail.com
}

Аннотация: В данной статье определена необходимость формирования правовых умений детей старшего дошкольного возраста в контексте меняющихся целей и парадигмы отечественного дошкольного образования. Проводится анализ содержательно-процессуальных особенностей педагогических условий формирования правовых умений детей старшего дошкольного возраста. Целью исследования является подтверждение методико-технологических параметров осуществления содержательно-процессуальных особенностей формирования правовых умений детей старшего дошкольного возраста.

Ключевые слова: правовое образование, дети старшего дошкольного возраста, формирование правовых умений детей старшего дошкольного возраста, содержательно-процессуальные особенности формирования правовых умений детей.

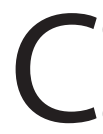
овременное российское общество диктует требования по повышению правовой грамотности населения. Индивидуальное правовое, гражданское, социальное развитие человека ведет к процветанию и укреплению государственности в целом. Обучение основам права должно начинаться с самого раннего возраста, так как знания, полученные в детстве, оказывают влияние на развитие личности человека всю его последующую жизнь [5].

Образовательный процесс детей в сфере права в условиях дошкольных образовательных организаций создается посредством сочетания игровой деятельности детей, познавательного коллективного процесса, где главным образом прививаются культурные особенности и правовые основы страны проживания. Фундаментом, на котором выстраивается образовательный процесс, являются возрастные, социальные и психофизические отличия детей дошкольного возраста. Толерантность, принятие культурных различий, социальная вовлеченность, коммуникативные способности как основополагающие аспекты развивающейся личности ребенка формируются также благодаря занятиям по правовому воспитанию и обучению.

Правовое образование детей дошкольного возраста невозможно без сформированной методики обучения, наглядно позволяющей показать ее структуру, содержание и специфику. Методика обучения - это объединенный комплекс главных закономерностей установления образовательной деятельности. Эффективность реализации методики формирования правовых умений детей старшего дошкольного возраста во многом зависит от правильного выбора комплекса педагогических условий. Педагогические условия определяются современными исследователями в области дошкольного образования как специально создаваемая педагогами среда, которая эффективно способствует усвоению детьми знаний и умений, формированию личных качеств детей, что в дальнейшем успешно способствует достижению поставленных воспитателем задач [3].

Внедряя выявленные педагогические условия в непосредственную экспериментальную работу, мы раскрываем суть содержательно-процессуальных особенностей, способствующих формированию правовых умений детей старшего дошкольного возраста, которые обозначили как: разработку программно-содержательного обеспечения правового образования детей старшего дошкольного возраста на основе инновационного типа обучения; создание и поддержание правовой предметно-пространственной развивающей среды; включение в образовательный процесс интерактивных правовых игр с применением экранных технологий. 
В экспериментальной работе осуществлялся отбор содержания образовательного материала, вводилась активная нормативно-правовая терминология, связанная с правовым образованием, способствующая формированию правовых умений, при этом обучение основам права способствовало целостному поликультурному, социальному, коммуникативному и толерантному развитию личности ребёнка. Разработанная методика формирования правовых умений детей старшего дошкольного возраста предполагает, что системообразующим фактором в проектировании педагогических условий может выступать образовательная программа, затем погружение ребенка в развивающую предметно-пространственную среду, где обучение основам права происходит через проявление интереса ребёнка к содержательному наполнению правовой пространственной среды во время его самостоятельной деятельности (знакомство с основными правами и свободами человека, социальными правилами поведения в обществе, основами гражданственности, толерантности, поликультурности), что способствует появлению у детей естественной потребности во взаимодействии со сверстниками и со взрослыми, приводящее к обучению социально-правовым нормам через совместную деятельность педагога с детьми путём организации интерактивных правовых игр, направленных на совершенствование правовых умений. Рассмотрим обозначенные содержательно-процессуальные особенности формирования правовых умений детей старшего дошкольного возраста более подробнее.

В рамках разработки программно-содержательного обеспечения правового образования детей старшего дошкольного возраста на основе инновационного типа обучения была составлена и согласована примерная программа «Основы правового образования детей старшего дошкольного возраста в условиях ДОО». Данная образовательная программа представляет собой изложение отдельных разделов, которые формируют содержание учебных вопросов, а также понятийно-терминологическое раскрытие, способы вычисления трудоемкости и результативности занятий. Отличительной особенностью образовательной программы является раскрытие форм организации образовательного процесса, на основании которых формируется учебно-познавательная деятельность (беседа, игра, конкурсы), а также указываются критерии, т.е. оценки на устанавливаемые задания-проверки. Цель составленной программы - интерактивное и игровое знакомство детей с основными правами человека, описанными во «Всемирной декларации прав человека» и «Конвенции о правах ребенка», развитие способности анализировать и оценивать поступки людей с правовой точки зрения, внедрять обучающие практические задания с намерением развить навыки применения полученных знаний в области права в реальной жизни. При этом велась активная познавательная деятельность, способствующая станов- лению навыкам межкультурного общения, пополнению словарного запаса, воспитанию толерантности, качеств высокой степени коммуникативности и контактности при общении с ровесниками [7].

Программа «Основы правового образования детей старшего дошкольного возраста в условиях ДОО» включает разделы: «Работа с педагогическим коллективом», «Работа с воспитанниками - детьми старшего дошкольного возраста (5-7 лет)», «Работа с родителями (законными представителями) воспитанников». Основной упор делается на раздел «Работа с воспитанниками - детьми старшего дошкольного возраста (5-7 лет)», который в рамках перспективного плана мероприятий содержит следующие подразделы - занятия: «Права и свободы детей» (начальное ознакомление детей с правами и свободами человека; элементарные представления о правовых нормах; ознакомление с «Конвенцией о правах ребёнка», «Декларацией прав человека»; начальные представление о культуре и праве своей страны и представления о культурно-социальных особенностях других народов); «Я и мои основные права» (формирование элементарных представлений о правах детей, правах человека); «Я и мои основные обязанности» (формирование элементарных представлений детей об обязанностях и правилах поведения в социуме); «Старая сказка на новый лад» (формирование оценочных суждений, воспитание чувства социальной справедливости); «Узнай сам, научи другого» (воспитание социальной активности, отзывчивости, развитие планирующей функции); «Я и моя группа» (формирование представлений о том, что у каждого человека есть свои интересы и предпочтения; помощь детям в установлении общности, объединения; формирование элементарных представлений о правовых взаимоотношениях сотрудников детского сада и детей); «Моя семья и право» (ознакомление детей с правом на любовь и заботу, формирование смысловых ориентиров значимости семьи для ребенка; формирование элементарные представления о правовых взаимоотношениях сотрудников детского сада, детей и родителей); «Как жить без ссор» (воспитание чувства социальной ответственности за свои поступки, формирование оценочных суждений, развитие чувства толерантности); «Сказочная страна «Права и свободы» (помощь детям закреплять, обобщать и уточнять полученный опыт по правовому образованию).

В рамках реализации данной программы для формирования правовых умений у детей старшего дошкольного возраста в условиях ДОО была разработана схема занятий (перспективное планирование) по правовому образованию в старшей группе детского сада.

Обучение и воспитание детей основам права должно носить образовательный характер и обязательно учитывать инновационные направления получения детьми 
знаний и умений. Основными методиками инновационного обучения можно назвать следующие: во-первых, обучение важно организовывать как систематическую самостоятельную исследовательскую деятельность детей; во-вторых, как развивающе-игровую, моделирующую деятельность; в-третьих, как коммуникативно-диалоговую деятельность и активный обмен мнениями и дискуссиями. Воспитатель несет роль помощника и партнера в расширении и освоении переживаемого опыта, а дети при этом занимают инициативную (субъектную) позицию. Обучение при этом осуществляется через стимулирование выполнения интерактивных игр, обеспечиваясь на базе инновационных образовательных технологий (информационные технологии, интерактивные правовые игры, игры с применением экранных технологий и др.) [1].

Таким образом, разработанная программа правового образования детей в условиях ДОО способствует становлению общих представлений детей о правах человека, получению знаний о социальной действительности, формированию начальных правовых умений и навыков, побуждению к грамотно-правовой деятельности. Программа строится на инновационных принципах личностного, развивающего и гуманистического характера взаимодействия взрослого и ребенка.

Создание и поддержание правовой предметно-пространственной развивающей среды, как следующая содержательно-процессуальная особенность формирования правовых умений детей старшего дошкольного возраста, способствует разностороннему и самостоятельному развитию каждого ребенка, дает возможность детям проявлять свои потенциальные способности, а педагогу помочь ребенку обнаружить и развить свои природные задатки.

«Среда» в педагогической и психологической литературе определяется как комплекс внешних факторов, влияющих на процесс развития человека. Среда условно разделяется на «макросреду» - особенности, климат национальной культуры и пр. и «микросреду» - семья, сверстники, дошкольные организации и т.д. Развивающая среда должна быть движущей силой всего процесса развития детей. Предметно-развивающая среда - это система материальных объектов деятельности ребенка, функционально моделирующая содержание его духовного и физического развития. Развивающая предметная среда представляет собой систему материальных объектов деятельности детей, совершенствующей их духовный и физический облик и предполагающей объединение социальных и природных факторов обеспечения разнообразной деятельности ребенка, учитывая, при этом, что игра должна все так же являться основной формой деятельности детей [2].
Правовой средой считаем конкретное социальноправовое пространство, с помощью которого ребенок включается в культурно-правовые связи общества. Это совокупность разных макро- и микро- условий его жизнедеятельности и социального-ролевого поведения, это также его случайные контакты и глубинные взаимодействия с другими людьми, конкретное природное, предметное окружение как открытая для взаимодействия часть социума. Правовая предметно-пространственная развивающая среда должна включать в себя: большую игровую площадку; разные типы игрового оборудования; игрушки различного вида; игровые атрибуты. Такая среда стимулирует ребенка на самостоятельную деятельность, развивая в нем умственные и творческие возможности, навыки общения, фантазию, личностные качества.

Основываясь на изучении психологической и педагогической литературы, разработали карту анализа правовой предметно-пространственной развивающей среды, которая состоит из двух частей - двух аспектов действия «средового» фактора: а) обеспечение открытого характера деятельности ДОО; б) организация предметно-пространственной среды правовой направленности в группе [3].

Первый аспект обеспечивает возможность контактов дошкольной образовательной организации с внеобразовательными структурами региона: приглашение на занятия, досуговые мероприятия в детском саду представителей социальных, культурных, спортивных, общественных организаций. Дети обогащают свои знания благодаря возможности общения с данными специалистами. Дошкольные организации знакомят детей старшего дошкольного возраста с основными нормами нравственно-правовых отношений, которые установлены обществом. Дети прорабатывают право каждого человека на свободное существование и уважение, право на имя, право обладать личными вещами, высказывать собственное мнение и относиться к другим людям с уважением. Особого внимания заслуживает факт того, что дошкольная организация работает как для взрослых, так и на благо детей, которые могут посещать различные социальные и культурные учреждения города. Дети могут сближаться со взрослыми благодаря прогулкам, экскурсиям по городу, посещать театры, музеи и т.д. Это позволит успешно развить в ребенке восприятие моделей общественного устройства, нравственно-правового поведения граждан в обществе, отрабатывать навыки общения и уважительного отношения к другим людям. Совместные посещения детьми и взрослыми различных мероприятий позволяет качественно скорректировать нравственно-правовые представления детей старшего дошкольного возраста.

Открытый характер работы доО обеспечивается 
системой конструктивного диалога и активным взаимодействием педагогов с родителями. Диалог - обязательный критерий функциональности образовательной организации в демократическом обществе. Данный диалог обеспечивается путем создания положительной эмоциональной среды в организации. Для формирования правовых умений детей старшего дошкольного возраста необходима совместная деятельность родителей и педагогов. Важной формой взаимодействия является приглашение родителей в качестве зрителей на открытые уроки в детском саду, где обсуждаются содержание, задачи и цели мероприятия. Педагоги имеют возможность посещать семьи, что становится привычным для родителей и радостным событием для детей. Воспитатели переодеваются в сказочных персонажей, героев книг, которые рассказывают интересные истории, расспрашивают о жизни семьи, дарят подарки и делают совместные фотографии. Родители вправе сами выбирать образовательные программы и технологии обучения детей, педагоги могут только подсказать лучшие варианты. Благодаря информированию родителей об используемых образовательных программах осуществляется реализация права детей на развитие и образование. Внедрение в педагогический процесс консультаций, наглядных рекомендаций, проведение «Дня открытых дверей», семинаров-практикумов повышает заинтересованность родителей и дает им возможность наиболее компетентно подходить к образованию детей.

Назначение среды гражданско-правовой направленности в группе дошкольной организации заключается в трансляции детям не только определенных нравственно-правовых сведений, но и в предоставлении им возможности закрепить навыки правовой культуры: детям предлагалось принимать участие в оформлении первых в их жизни «документов», содержащих правила и обязанности всех участников педагогического процесса; в группах создавались специальные пространства для активной познавательной и двигательной деятельности; использовался различный правовой интерьер и атрибутика; оформлялись личные шкафчики детей и уголки самостоятельной работы; создавались места для отдыха и тихих игр, размышлений, наблюдений, рассуждений, оформленные репродукциями картин с образцами государственной символики; выделялись специальные помещения для работы с родителями [4].

Таким образом, правовая предметно-пространственная развивающая среда включая предметы, вещи, образы, знаки, символы, в которых отражается культура и правовые установки поколений разных народов, опыт, знания и умения, накопленные человечеством, влияет на формирование отношения личности к ценностям, труду, творчеству, миру в целом, которые в итоге служат развитию и саморазвитию детей.
Включение в образовательный процесс интерактивных правовых игр с применением экранных технологий - третье условие успешной реализации методики формирования правовых умений детей старшего дошкольного возраста. С первых дней своего существования, с самого начала своей жизни ребенок усваивает определенный социальный опыт, контактируя с другими людьми, который, являясь субъективно приобретаемым, превращается в неотъемлемую часть его личности. Главнейшим помощником при становлении социализации детей может стать интерактивная игра, так как интерактивные методы, в отличие от активных, ориентированы на более широкое взаимодействие детей дошкольного возраста как с воспитателем, так и друг с другом [2].

Использование интерактивных форм правового обучения предполагает работу в статичных парах или парах сменного состава, ротационных (сменных) тройках, работу в малых группах (иллюстрирование сказок и рассказов, изготовление художественных макетов и стендов и т.д.); игровое сотрудничество (круглые столы, конференции, ролевые и сюжетные игры и др.). Занятия рекомендуется проводить в различных формах: праздник, игры (настольные, ролевые, подвижные, интеллектуальные), викторины, конкурсы, мини-спектакли («Уроки Буратино», «Юный гражданин», «Путешествие в страну права», «Какое право нарушено», «Я не должен», «Поступаем правильно» и др.).

Исследование показало, что наибольшей эффективностью обладают индивидуальная и групповая формы, поскольку в первой педагог может определить слабое усвоение некоторых знаний и улучшить ситуацию, а во второй дети повторяют друг за другом и выполняют работу сообща.

Суть интерактивных форм правового образования состоит в том, чтобы определить детей и воспитателя как субъектов учебного процесса. При этом педагог - это организатор процесса обучения, он создает среду для выражения детской инициативности за счет вовлечения в творческую деятельность. На формирование правовых умений детей старшего дошкольного возраста, развитие их фантазии, самостоятельности и творческого мышления влияют работа над проектами, дидактические игры, детские постановки и спектакли. К примеру, осуществление проектов должно проходить как на занятиях, так и в домашних условиях благодаря помощи родителей («Моя семья», «Сказочные правила», «Наши права и обязанности» и т.д.). Детям предлагается раскрасить тематические картинки, сделать аппликации и открытки, так как возможность изобразительной деятельности положительно сказывалась на воспитании социально-правовой развивающейся личности.

Применение экранных технологий на занятиях по 
обучению основам права позволяло одновременно работать с текстом, графическим изображением, видео и аудиоматериалами, при этом управление процессом работы осуществлялось при помощи указки на поверхности интерактивной доски «Smart Board», представляющей собой сенсорный экран, работающий как часть системы, в которую входит проектор и компьютер. Для работы с интерактивной доской педагогом тщательно подбираются материалы, соответствующие возрасту детей и выстраивающиеся по перспективному тематическому плану.

При работе на данном оборудовании решались вопросы, связанные с формированием когнитивной сферы и способности детей к творчеству, развивались воображение, фантазия и желание познавать; вырабатывалась готовность ребенка к дальнейшему обучению; осуществлялось ознакомление детей с компьютером и той пользой, которую он несет обществу; прививалось чувство гуманности и бережного отношения к окружающему миру. Благодаря «Smart Board» дети могут визуально запоминать новые слова и понятия, сопровождаемые иллюстрациями, сами выполнять рисунки с помощью специальных маркеров. Поверхность доски «Smart Board» имеет большую площадь, что позволяет использовать ее для совместных игр с детьми. Применяется подход к обучению «здесь и сейчас», в котором дети принимают непосредственное участие: используются большие иллюстрации, можно менять местами буквы и цифры, осуществлять действия с разными объектами. Перечисленное позволяет осваивать новый материал быстрее и эффективнее. При этом применяется визуальная методика восприятия иллюстрированного материала [6].

Целевое использование экранных технологий на уроках правового образования является необходимым и учитывает специфику предмета. Основной задачей являлось ознакомление с новым материалом по праву, включающим важные понятия и суждения. Процесс занятий выстраивался таким образом, чтобы дети могли воспринимать на слух новую информацию, произносить понятия в микрофон, выполнять грамматические упражнения, разгадывать кроссворды, осуществлять дидактические задания, выводимые на экран интерактивной сенсорной доски. Возможности экранных технологий также позволяют чередовать аудио и видео материалы, поскольку применение анимации привлекает маленьких учеников, делает их активными. Подача материала в качестве мультимедийной презентации в значительной степени сокращает временные затраты на процесс обучения и, следовательно, бережет здоровье детей. Просмотр анимированных песен и мультфильмов «Красная Шапочка», «Снегурочка», «Айболит», «Гуси-лебеди», «Буратино» помогает развитию слуховой памяти детей, восприятию речи на слух.

Таким образом, использование интерактивных правовых игр с применением экранных технологий способствует увеличению объема новой информации, позволяет обогатить полученные ранее знания, способствует быстрому и правильному пониманию материала, который транслируется посредством экрана, позволяет комментировать происходящее и предлагать целесообразную оценку. В целом применение интерактивных игр и экранных технологий оптимизирует процесс перехода от наглядно-образного к абстрактному мышлению.

Резюмируя вышесказанное, отметим, что выявленная совокупность методико-технологических параметров осуществления содержательно-процессуальных особенностей формирования правовых умений детей старшего дошкольного возраста способствует реализации методики и влияет на результативность применяемых педагогических условий. Разработка программно-содержательного обеспечения правового образования детей на основе инновационного обучения, последующее погружение ребенка в созданную правовую предметнопространственную развивающую среду, применение в образовательном процессе интерактивных правовых игр с использованием экранных технологий оказывает эффективное влияние на обучение ребёнка основам права, на формирование правовой грамотной личности.

\section{ЛИТЕРАТУРА}

1. Васякина, А.С., Шепилова, Н.А. Профессиональная готовность педагогов ДО0 к инновационной деятельности // Международный студенческий научный вестник. - 2015. - № 5-3. С. 353-354.

2. Гусева, Н.Г. Дидактическая игра как средство формирования основ правовых знаний детей старшего дошкольного возраста // Наука, образование, общество: тенденции и перспективы развития. Чебоксары: ЦНС «Интерактив плюс». - 2017. - С. 136-139.

3. Елисеенко, О.В. Педагогические условия формирования правовых умений детей старшего дошкольного возраста / 0.В. Елисеенко // Мир науки, культуры, образования. - 2020. - № 4 (83). - С. 171-175.

4. Козлова, С.А. Теория и методика ознакомления дошкольников с социальной действительностью: учеб. пособие для сред. пед. учеб. заведений / С.А. Козлова. - Москва: Академия, - 2008. - 158 с.

5. Никитина, Е.Ю., Елисеенко, О.В. Теоретические аспекты проблемы формирования правовых умений детей старшего дошкольного возраста // Вестник Челябинского государственного педагогического университета. Челябинск. - 2018; - № 6: - С.159-172. 
6. Никитина, Е.Ю., Химичева, Д.П. Теоретические аспекты проблемы применения информационно-коммуникационных технологий как средства активизации познавательной деятельности детей старшего дошкольного возраста // Вестник Челябинского государственного педагогического университета. Челябинск. - 2018; - № 7: - С. $126-137$.

7. Правовое воспитание в детском саду: программа и методические рекомендации / отв. ред. В.М. Сапогов. - Псков: ПОИПКР0. - 2008. - 159 с.

( Елисеенко Ольга Викторовна (eliseenkoov@gmail.com).

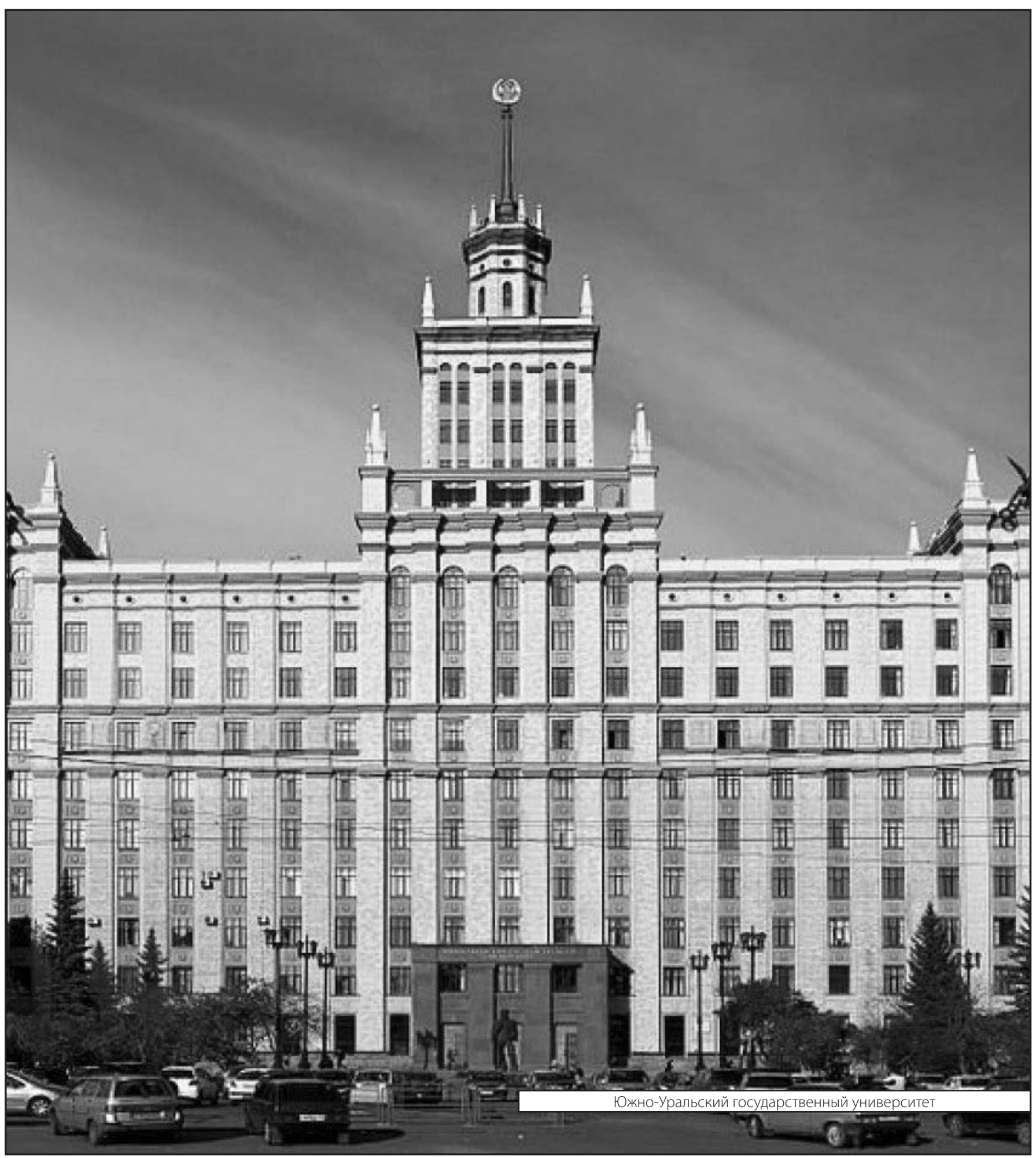

